\title{
The organotypic culture of HPV-transformed keratinocytes: an effective in vitro model for the development of new immunotherapeutic approaches for mucosal (pre)neoplastic lesions
}

\author{
P. Delvenne *, P. Hubert, N. Jacobs, S.L. Giannini, L. Havard, I. Renard, \\ D. Saboulard, J. Boniver
}

Department of Pathology B35, University Hospital of Liège, CHU Sart Tilman, 4000 Liège, Belgium

\begin{abstract}
The purpose of this study is to develop a reliable in vitro human model to test new immunotherapeutic approaches for squamous cell carcinoma that develop on mucosal surfaces. The organotypic (raft) culture permits cells to proliferate and differentiate at an air-liquid interface on a dermal equivalent support. Normal keratinocytes stratify and fully differentiate in a manner similar to the normal squamous epithelial tissues, while human papillomavirus-immortalized and established squamous carcinoma cell lines exhibit dysplastic morphologies similar to (pre)neoplastic lesions seen in vivo. We have demonstrated the ability of these organotypic cultures to be manipulated by altering the epithelial stratification with cytokines (interferon- $\gamma$ and tumor necrosis factor- $\alpha$ ) and by integrating activated lymphocytes or dendritic cells into the in vitro formed epithelial sheet. This model may provide a useful tool to investigate the factors contributing to the presence and function of immunocompetent cells within a neoplastic epithelium that develops on a mucosal surface. (C) 2001 Elsevier Science Ltd. All rights reserved.
\end{abstract}

Keywords: Organotypic culture; Human papillomavirus; Immunotherapy

\section{Introduction}

Cancers associated with potentially oncogenic viruses represent good models for research aimed at developing anti-tumoral vaccines since viral proteins could serve as tumor antigens. One of the most actively investigated examples of a tumor-associated virus is the human papillomavirus (HPV). Infection by specific types of HPV (most notably HPV 16 and HPV 18) is strongly implicated as a causative agent in the etiology of cervical cancer and its precursors, which are designated as cervical intraepithelial neoplasia or squamous intraepithelial lesions (SILs) (for a review, see Ref. [1]). The generation of an effective protective immune response in tumors is, however, still poorly understood and may be influenced by factors produced by neoplastic and infiltrating immune cells. Because different patterns of synergism or antagonism may be observed between

\footnotetext{
* Corresponding author. Tel: +32-43-662564; Fax: + 32-43662919.

E-mail address: p.delvenne@ulg.ac.be (P. Delvenne).
}

these factors, preliminary studies of immunotherapeutic manipulations should be performed in models approximating the in vivo environment of the tissue of origin.

The purpose of this study is to develop a reliable in vitro human model to test new immunotherapeutic approaches for squamous cell carcinoma that develop on mucosal surfaces and particularly in the uterine cervix. The organotypic (raft) culture permits cells to proliferate and differentiate at an air-liquid interface on a dermal-equivalent support. Normal keratinocytes stratify and fully differentiate in a manner similar to the normal squamous epithelial tissues, while HPV-immortalized and established squamous carcinoma cell lines exhibit dysplastic morphologies similar to (pre)neoplastic lesions seen in vivo. The ability of these organotypic cultures to be manipulated may provide a useful tool to investigate the immune factors contributing to eliminate a neoplastic epithelium developed on a mucosal surface.

Interferon-gamma (IFN- $\gamma)$ and tumor necrosis factor-alpha (TNF- $\alpha)$ are regulatory cytokines with pleiotropic biological activities including antiprolifera- 
tive, antiviral and immunomodulatory activities [2-5]. They are capable of modulating the expression of cell surface molecules, e.g. HLA class II antigens and intercellular adhesion molecules, with a pivotal role in the interactions of neoplastic or infected cells with the host's immune system [4]. The loss of responsiveness to these cytokines by neoplastic keratinocytes might represent a potential mechanism by which the transformed cells escape destruction by the host's immune system.

The most effective mechanism for tumor cell destruction is likely to be cytotoxic $\mathrm{T}$ lymphocyte (CTL) responses. T lymphocytes are observed in HPV-associated cervical lesions but there is some evidence that they are poorly activated [6]. Specific CTL against HPV have been detected in $\mathrm{T}$ lymphocytes infiltrating cervical lesions, but only in a minority of patients [7]. Professional antigen-presenting cells, such as Langerhans cells, also exhibit quantitative and qualitative alterations in SILs [8-11].

In this study, we demonstrated that the organotypic culture of HPV-transformed keratinocytes is a convenient and bona fide in vitro model to examine the effect of cytokines on the growth of HPV-transformed keratinocytes and the ability of immunocompetent cells to infiltrate a (pre)neoplastic epithelium.

\section{Materials and methods}

\subsection{Culture of normal cervical keratinocytes}

Human exocervical epithelial cells were obtained from hysterectomy specimens of healthy women. The operations were performed for disease unrelated to the cervix. Cell cultures were established and maintained following a previously reported method [12]. Subconfluent cultures were dispersed with $0.0025 \%$ trypsin and $0.02 \%$ ethylenediamine tetraacetic acid. These primary cultures of keratinocytes were used for the organotypic cultures.

\subsection{HPV-transformed keratinocyte cell lines}

$\mathrm{SiHa}$, CasKi, and C4-II are tumorigenic cervical carcinoma-derived keratinocyte cell lines [13-15]. The SiHa cell line contains one copy of integrated HPV 16 DNA. The CasKi cell line contains approximately 600 copies of integrated HPV 16 DNA, whereas the C4-II cell line contains HPV 18 DNA sequences. The CK2 cell line was established by transfection of human cervical keratinocytes with HPV-33 DNA and is not tumorigenic in nude mice [12]. Two cell lines (supplied by Dr J.K. McDougall) established by transfection of human foreskin keratinocytes with HPV 16 DNA (EIL8; nontumorigenic) or HPV 18 DNA (18-11S3; tumorigenic after 60 passages in tissue culture) were also tested for response to IFN- $\gamma$ and/or TNF- $\alpha$ [16]. All these HPVtransformed keratinocyte cell lines were grown and maintained in a mixture of HAM F12 and DMEM supplemented with the same additives as those used for normal keratinocyte cultures.

\subsection{Cytokines}

Human rIFN- $\gamma\left(2 \times 10^{7} \mathrm{U} / \mathrm{mg}\right)$ and $\operatorname{rTNF}-\alpha(4.9 \times$ $10^{7} \mathrm{U} / \mathrm{mg}$ ) were kindly provided by Boehringer Ingelheim International. IFN- $\gamma$ and $\mathrm{TNF}-\alpha$ production in peripheral blood mononuclear cell (PBMC) cultures was determined using an ELISA assay (Medgenix Diagnostics S.A. Fleurus, Belgium).

\subsection{PBMC cultures}

PBMC were isolated from the buffy coat of healthy donors by centrifugation on Lymphoprep (Nycomed, Oslo, Norway) following standard protocols. For stimulation, cells were cultivated $\left(1.25 \times 10^{6}\right.$ cells $\left./ \mathrm{ml}\right)$ in the presence of $10 \mathrm{ng} / \mathrm{ml}$ anti-CD3 mAb kindly provided by Dr Kurrle Behringwerke (Marburg, Germany) and/or $50 \mathrm{U} / \mathrm{ml}$ human rIL-2 kindly provided by Glaxo Institute for Molecular Biology (AG, Genève, Switzerland) during 4 days.

\subsection{Dendritic cell cultures}

Dendritic cells (DC) were generated by culturing adherent fractions of human PBMC as previously described [17]. The phenotype of the cells was verified by flow cytometric cell surface marker analysis using anti-CD14, anti-CD1a, anti-CD4 and anti-CD3 antibodies.

\subsection{Organotypic cultures}

Organotypic cultures of normal cervical keratinocytes and HPV-transformed keratinocytes were prepared by using procedures slightly modified from those described previously [16]. For the preparation of dermal equivalents, a collagen matrix solution was made with $32 \mathrm{mg}$ collagen (cellagen solution AC-5, type I; ICN Biomedical, Asse-Relegen, Belgium) mixed on ice with $1.6 \mathrm{ml}$ of $0.1 \%$ acetic acid, $1 \mathrm{ml}$ chilled tenfold concentrated Hank's buffer supplemented with phenol red and $1 \mathrm{~N} \mathrm{NaOH}$ to give $\mathrm{pH}$ 7.2. One milliliter of fetal calf serum containing $4 \times 10^{5}$ normal human fibroblasts was then added. One milliliter of the collagen-fibroblasts solution was poured into 24 -well plates (Nunclon $\Delta$ Multidishes, NUNC, Denmark) and allowed to solidify at $37^{\circ} \mathrm{C}$ for $1 \mathrm{H}$. The final concentrations of collagen and fibroblasts were $3.2 \mathrm{mg} / \mathrm{ml}$ and $4 \times 10^{4}$ cells $/ \mathrm{ml}$, respectively. After gel equilibration with $1 \mathrm{ml}$ growth 
medium overnight at $37^{\circ} \mathrm{C}, 25 \times 10^{4}-1 \times 10^{6}$ keratinocytes (normal or HPV-transformed) resuspended in $100 \mu \mathrm{l}$ growth medium were seeded on top of the gels and maintained submerged for 24-96 h. The collagen rafts were raised in a $25 \mathrm{~mm}$ tissue culture insert $(8 \mu \mathrm{m}$ pore size; NUNC, Denmark) and placed onto stainlesssteel grids, at the interface between air and liquid culture medium. Epithelial cells were then allowed to stratify for 10-15 days. Hematoxylin eosin staining and standard immunohistological techniques with antibodies against markers of cell proliferation (MIB-1; Immunotech S.A.), differentiation (involucrin; Novocastra), cell adhesion (E-cadherin, HECD-1; Boehringer Ingelheim International) were first used to assess the degree of similarity between the in vitro formed epithelial sheet and the in vivo observed epithelium. We next determined whether these organotypic cultures can be manipulated. For the cytokine experiments, medium added or not with either IFN- $\gamma(1000$ $\mathrm{U} / \mathrm{ml})$, TNF- $\alpha(1000 \mathrm{U} / \mathrm{ml})$ or IFN- $\gamma(1000 \mathrm{U} / \mathrm{ml})$ in combination with TNF- $\alpha(1000 \mathrm{U} / \mathrm{ml})$ was changed every $2-3$ days. Organotypic cultures then were fixed in $10 \%$ neutral buffered formaldehyde, paraffinembedded, sectioned and stained with hematoxylin and eosin or immunolabeled with the MIB-1 monoclonal antibody specific for Ki-67 antigen. For other experiments, the PBMC and DC were seeded on top of the in vitro formed epithelium after stratification of keratinocyte. The PBMC and DC concentrations were $10^{6}$ cells $/ 50 \mu \mathrm{l}$ and $2 \times 10^{5}$ cells $/ 50 \mu \mathrm{l}$ growth medium, respectively. For the DC experiments, organotypic culture medium was supplemented or not with $800 \mathrm{U} / \mathrm{ml}$ granulocyte macrophage-colony stimulating factor (GM-CSF). After $24-72 \mathrm{~h}$ at $37^{\circ} \mathrm{C}$, the collagen rafts were harvested. The cultures were then embedded in O.C.T. compound (Tissue Tek, Sakura, Netherlands) at $-70^{\circ} \mathrm{C}$ and sectioned with a cryostat microtome for the immunohistochemical analysis. The density of $\mathrm{T}$ lymphocytes and DC migrating into the epithelial layer was assessed by a standard avidin-biotin-peroxidase technique with monoclonal antibodies specific for CD3, CD45 (Becton Dickinson, Erembodegem, Belgium) and CD1a (clone NA1/34 from Dako, Glostrup, Denmark).

\subsection{MTT assay}

$\mathrm{HPV}^{+}$cell lines were seeded at a concentration of $2.5 \times 10^{3}$ cells $/$ microwell in $200 \mu \mathrm{l}$ culture medium containing 100 or $25 \mu 1$ PBMC culture supernatant. The cells were incubated 4 days at $37^{\circ} \mathrm{C}$ and $5 \% \mathrm{CO}_{2}$. In each well, $10 \mu \mathrm{l}$ cell proliferation reagent WTS-1 (tetrazolium salt; Boehringer Mannheim) were added and incubated for $4 \mathrm{~h}$ at $37^{\circ} \mathrm{C}$ and $5 \% \mathrm{CO}_{2}$. The absorbance of the sample was measured at $440 \mathrm{~nm}$ with a microtiter plate reader.

\section{Results}

3.1. Assessment of the degree of similarity between the in vitro formed epithelial sheet and the in vivo observed epithelium

After 10-15 days, normal keratinocytes produced differentiated epithelial layers of about ten cells in thickness morphologically similar to a normal squamous exocervical epithelium (Fig. 1A,B), whereas HPV-transformed keratinocytes produced an epithelial sheet of up to 10-15 cells in thickness [18] (Fig. 1C). These cells appeared disorganized and highly atypical throughout its full thickness, reminiscent of high-grade cervical lesions (Fig. 1D). Ki-67 antigen was expressed throughout the full thickness of the epithelium, as already observed in biopsy specimens of high-grade SIL [9] (Fig. 1E,F). In contrast, the normal cervix and normal keratinocyte raft cultures showed important staining for the differentiation marker, involucrin, whereas this staining was absent or limited to the superficial cell layers for both $\mathrm{HPV}^{+}$keratinocyte raft cultures and (pre)neoplastic lesions of the cervix (data not shown). There was also a decreased cell membrane staining of the cell adhesion molecule, E-cadherin, in SILs of the cervix and in organotypic cultures of HPVtransformed keratinocytes compared with the normal exocervical epithelium and organotypic cultures of normal keratinocytes (data not shown).

\subsection{Effect of IFN- $\gamma$ and $T N F-\alpha$ on normal and $H P V$-transformed keratinocytes in organotypic cultures}

The growth of normal keratinocytes in organotypic cultures was inhibited by IFN- $\gamma$, TNF- $\alpha$ and IFN- $\gamma$ associated to TNF- $\alpha$. This antiproliferative effect of cytokines was reflected by the impairment of normal epithelial stratification that was reduced to a few cells in thickness. The stratification and immunostaining for Ki-67 antigen of HPV-transformed keratinocytes were dramatically decreased in the presence of IFN- $\gamma$ and IFN- $\gamma$ associated to TNF- $\alpha$ (Fig. 2A,B). A more pronounced effect was observed with the combination of IFN- $\gamma$ and TNF- $\alpha$. TNF- $\alpha$ alone, at a concentration of $1000 \mathrm{U} / \mathrm{ml}$, did not significantly alter the stratificationproliferation of the HPV-transformed cell lines [18].

\subsection{Infiltration of PBMC into organotypic cultures of $H P V$-transformed keratinocytes}

After $24 \mathrm{~h}$ of co-culture with the keratinocyte rafts, mononuclear cells (detected by anti-CD45 mAb) were observed in the epithelial sheet. The majority of these cells were $\mathrm{T}$ lymphocytes as shown by the anti-CD3 labeling (data not shown). The density of IL-2 + antiCD3 mAb-stimulated PBMC infiltrating the epithelial 

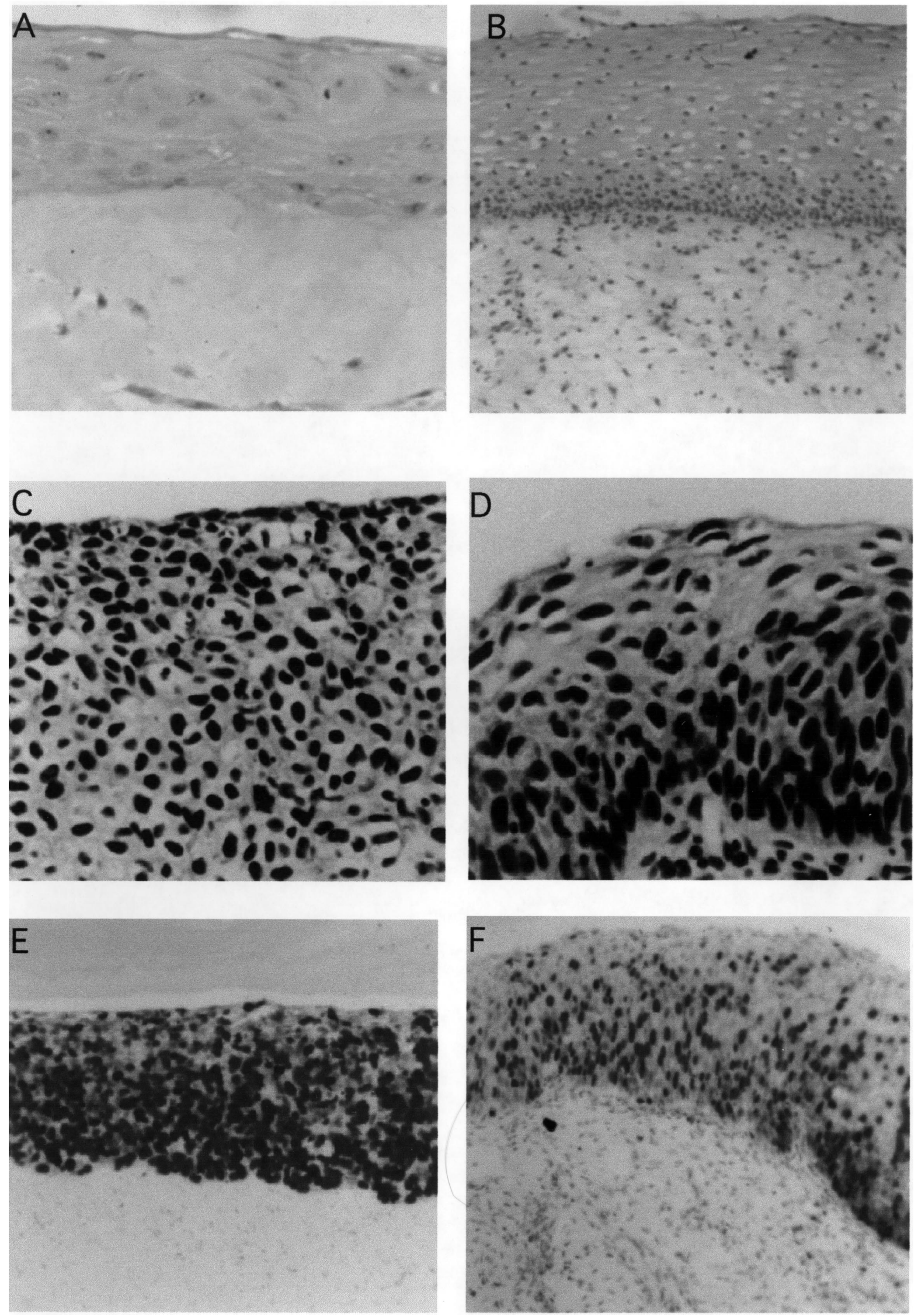

Fig. 1. Normal and HPV-transformed keratinocyte organotypic cultures as models of normal squamous epithelium and high-grade cervical lesions, respectively (A-D: hematoxylin-eosin). (A) Section of an organotypic culture of normal cervical keratinocytes. (B) Biopsy specimen of normal exocervical squamous epithelium. (C) Section of an organotypic culture of SiHa cells. (D) Biopsy specimen of high-grade cervical SIL. (E-F) Ki67 antigen-immunostained sections of an organotypic culture of HPV-transformed keratinocytes (E) and a biopsy specimen of high-grade cervical lesion $(\mathrm{F})$. 

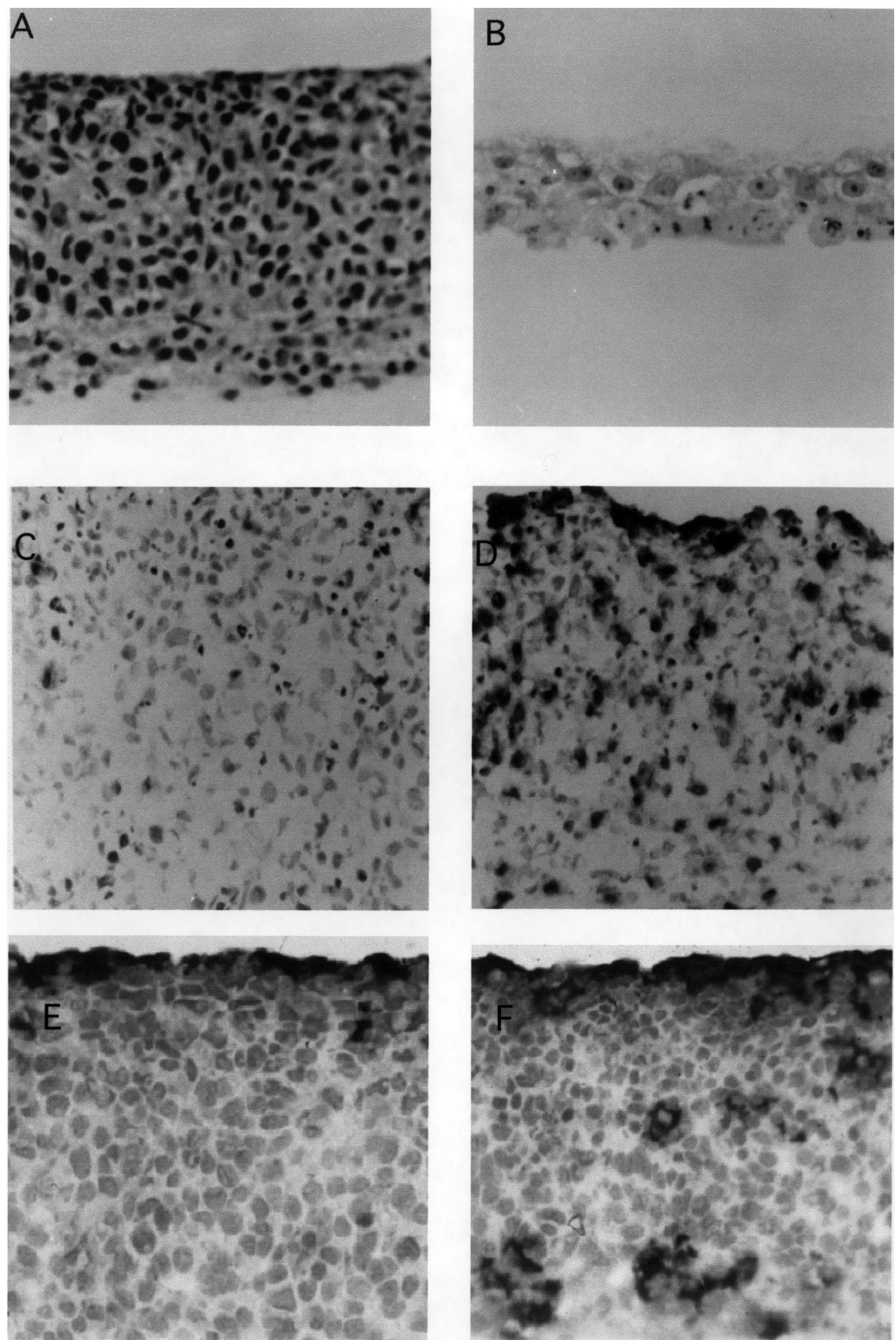

Fig. 2. Representative examples of organotypic cultures of HPV-transformed keratinocytes supplemented by cytokines and/or infiltrated by immunocompetent cells. Hematoxylin-eosin stained sections of organotypic cultures of SiHa cells in the absence (A) or in the presence (B) of IFNg associated with TNFa. CD45-immunolabeled sections of organotypic cultures of SiHa cells infiltrated by resting PBMC (C) or by PBMC stimulated with IL-2 + anti-CD3 (D). CD1a-immunolabeled sections of organotypic cultures of SiHa cells infiltrated by dendritic cells in the absence $(\mathrm{E})$ or in the presence $(\mathrm{F})$ of GM-CSF. 


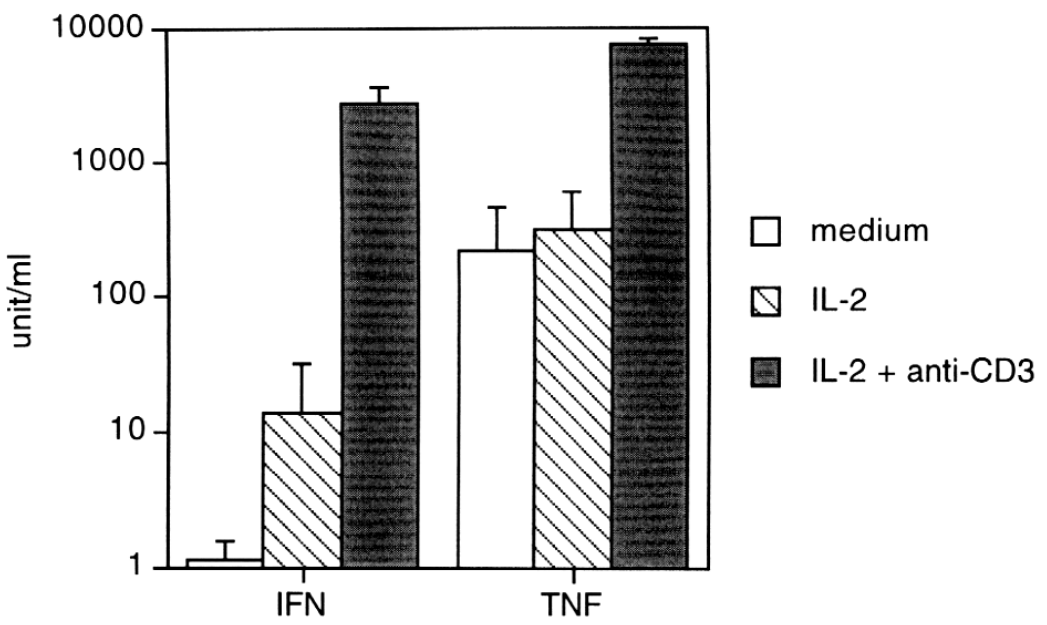

Fig. 3. IFN- $\gamma$ and TNF- $\alpha$ production in cultures of unstimulated (medium) or stimulated PBMC (IL-2 or IL-2 + anti-CD3 mAb).

sheet was higher than that of unstimulated or IL-2stimulated T lymphocytes (Fig. 2C,D). These PBMC had a cytotoxic effect since apoptotic keratinocytes were detected in organotypic cultures [19]. Interestingly, IL-2 + anti-CD3 mAb-activated PBMC produced high amounts of IFN- $\gamma$ and TNF- $\alpha$ (Fig. 3), and the supernatant of these cultures inhibited the proliferation of $\mathrm{HPV}^{+}$cell lines (Fig. 4), suggesting that IFN- $\gamma$ and TNF- $\alpha$ could participate in the cytotoxic effect observed in organotypic cultures.

\subsection{Infiltration of DC into organotypic cultures of $H P V$-transformed keratinocytes}

Fig. 2E-F illustrates representative experiments showing the density of CDla-labeled DC in HPV-transformed organotypic cultures incubated with or without exogenous GM-CSF. In organotypic cultures of normal keratinocytes, DC migrated in a similar manner in the presence or in the absence of GM-CSF [20]. In contrast, DC layered onto organotypic cultures of $\mathrm{SiHa}$ poorly infiltrated the epithelial layer in the absence of GM-CSF (Fig. 2E), whereas addition of GM-CSF caused an important increase in the density of DC observed in the epithelial layer (Fig. 2F).

\section{Discussion}

Because the validation of new treatments based on the stimulation of the immune system of the host may benefit from studies performed with in vitro models mimicking many in vivo features, we developed an organotypic culture system that permits epithelial cells to proliferate and differentiate at an air-liquid interface on a dermal equivalent support. Normal keratinocytes stratify and fully differentiate in a manner similar to the normal squamous epithelial tissues, while HPV-immor- talized and established squamous carcinoma cell lines exhibit dysplastic morphologies similar to (pre)neoplastic squamous lesions seen in vivo.

Morphological and immunohistological techniques with antibodies against markers of cell proliferation, differentiation, and cell adhesion were first used to assess the degree of similarity between the in vitro formed epithelial sheet and the in vivo observed epithelium. Our results demonstrated that the organotypic (raft) culture is not simply constituted by a random accumulation of cells, but also reproduces faithfully normal or (pre)neoplastic epithelial tissues, as observed in vivo. We next demonstrated the ability of these

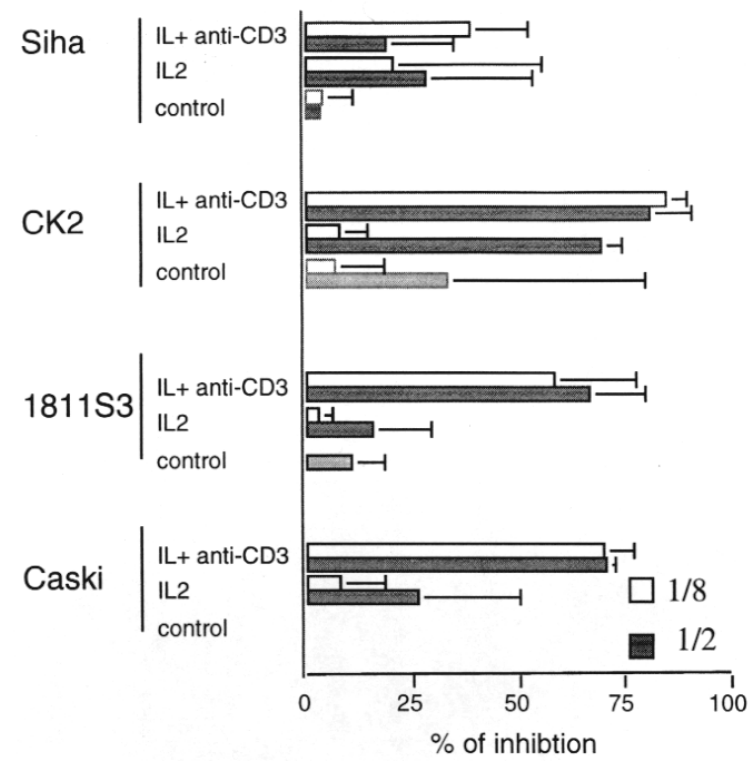

Fig. 4. Inhibition of $\mathrm{HPV}^{+}$cell line proliferation by culture supernatants of unstimulated (medium) or stimulated PBMC (IL-2 or IL-2 + anti-CD3 mAb). Two dilutions of supernatants were used $(1 / 2$ and $1 / 8)$. Means $\pm S, D$, of two or three independent experiments are shown. 
organotypic cultures to be manipulated. We showed that HPV-transformed keratinocytes do not lose their sensitivity to the antiproliferative effect of IFN- $\gamma$ alone or associated with TNF- $\alpha$, compared with normal keratinocytes. These results associated to the demonstration of a localized immunodepletion in HPV-related lesions [10,21] suggest that these recombinant cytokines might be useful in the treatment of cervical HPV-associated cervical lesions. We also succeeded to integrate in these in vitro formed epithelial sheets some types of immunocompetent cells. Since intra-epithelial $T$ lymphocytes have been shown to be depleted in cervical SIL [22,23] and to increase in spontaneously regressing HPV-associated genital warts [24], the cell-mediated immune response probably plays a crucial role in host defence against HPV infection and associated(pre)cancerous lesions, perhaps via the production of IFN- $\gamma$ and TNF- $\alpha$. The establishment of an in vitro model allowing for the investigation of the factors contributing to the presence and function of immunocompetent cells within a dysplastic epithelium is therefore relevant. Since tissue cells cultivated on plastic are in an environment that does not prevail in vivo, organotypic cultures present a very promising in vitro model for testing the ability of immune cells to infiltrate a pre-neoplastic epithelium. To evaluate the feasibility of this model, as a first step, we have studied the infiltration of resting and activated allogeneic PBMC into an organotypic culture of HPV-transformed keratinocytes. The PBMC were activated by IL-2 and IL- $2+$ antiCD3 to allow the generation of LAK cells, as already used in immunotherapeutical protocols [25]. The activation in the presence of anti-CD3 $\mathrm{mAb}$ induced an increase in the proportion of $\mathrm{T}$ lymphocytes as we previously showed [26]. Although unstimulated and stimulated lymphocytes were able to penetrate $\mathrm{SiHa}$ organotypic cultures, the stimulated lymphocytes infiltrated the cultures more rapidly and in higher numbers, especially after activation with IL-2 + anti-CD3 $\mathrm{mAb}$. Most of the infiltrating lymphocytes were $\mathrm{T}$ cells. These results highlight the potential interest of organotypic cultures of HPV-transformed keratinocytes as a model for studying the ability of lymphocytes to migrate into a (pre)neoplastic epithelium. Other models are, however, necessary to analyse the ability of lymphoid cells to cross the basement membrane, such as those using a three-dimensional collagen matrix $[27,28]$.

As most pre-neoplastic lesions of the cervix are associated with a significant depletion of intra-epithelial Langerhans cells, when compared with normal cervix epithelium [8,9,11], we also investigated the migration of in vitro generated $\mathrm{DC}$ in the presence of keratinocytes derived from normal cervix and HPV-transformed cell lines in organotypic cultures. We and other workers have observed that $\mathrm{HPV}^{+}$keratinocytes cell lines produce less GM-CSF than normal keratinocytes [29]. Since GM-CSF is an essential factor not only for the maturation and differentiation of DC but also for their motility [30], we tested the capacity of this cytokine to influence the ability of DC to colonize an in vitro formed (pre)neoplastic epithelium. Under basal conditions, the level of DC infiltration in cultures of normal keratinocytes was higher than that of $\mathrm{HPV}^{+}$ cell lines cultures. Except for one cell line, a positive correlation was observed for the numbers of $\mathrm{CDla}^{+}$ cells present in the epithelial layer and the amount of GM-CSF produced by the $\mathrm{HPV}^{+}$cell lines (data not shown). When the medium of organotypic cultures of $\mathrm{HPV}^{+}$cell lines was supplemented with GM-CSF, the infiltration of DC improved and reached an infiltration level equivalent to that obtained with normal keratinocytes. These findings suggest that a treatment based on GM-CSF may restore some immunologic functions that have been shown to be altered during the progression of cervical SILs.

In conclusion, this study highlights the potential interest of the organotypic culture of HPV-transformed keratinocytes for the design of new immunotherapeutic strategies. The ability of this model to be manipulated (for example, by integrating cytokines and/or immunocompetent cells) may also provide a useful tool to investigate the factors contributing to the presence and function of immunocompetent cells within a neoplastic epithelium.

\section{Acknowledgements}

This work was supported by the Belgian National Fund for Scientific Research, the 'Centre de Recherche Interuniversitaire en Vaccinologie (Convention 3073, with SmithKline Beecham Biologicals and the Walloon Region)', the 'Centre Anticancéreux près l'Université de Liège' and UE contract (BIO4-CT98-0097). P.D. and N.J. are research associates of the Belgian National Fund for Scientific Research. The authors wish to acknowledge E. Franzen-Detrooz for her excellent technical assistance.

\section{References}

[1] zur Hausen H. Viruses in human tumors: reminiscences and perspectives. Adv Cancer Res 1996;68:1-22.

[2] Lewis GD, Aggarwal BB, Eessalu TE, Sugarman BJ, Shephard HM. Modulation of the growth of transformed cells by human tumour necrosis factor- $\alpha$ and interferon- $\gamma$. Cancer Res 1987;47:5382.

[3] Talmadge JE, Tribble HR, Pennington RW, Philips H, Wiltrout RH. Immunomodulatory and immunotherapeutic properties of recombinant $\gamma$-interferon and recombinant tumor necrosis factor in mice. Cancer Res 1987;47:2563. 
[4] Nickoloff BJ, Turka LA. Keratinocytes: key immunocytes of the integument. Am J Pathol 1993;143:325-31.

[5] Yu WG, Yamamoto N, Takenaka H, Mu J, Tai XG, Zou JP, Ogawa M, Tsutsui T, Wiljesuria R, Yoshida R, Herrmann S, Fujiwara H, Hamaoka T. Molecular mechanisms underlying IFN- $\gamma$-mediated tumor growth inhibition induced during tumor immunotherapy with rIL-12. Int Immunol 1996;8:855-65.

[6] Ghosh AK, Moore M. Tumor infiltrating lymphocytes in cervical carcinoma. Eur J Cancer 1992;11:1910-6.

[7] Evans E, Man S, Evans AS, Borysiewicz LK. Infiltration of cervical tissue with human papillomavirus-specific cytotoxic Tlymphocytes. Cancer Res 1997;57:2943-50.

[8] Viac J, Guerin-Reverchon Y, Chardonnet Y, Bremond A. Langerhans cell and epithelial cell modifications in cervical intraepithelial neoplasia: correlation with human papillomavirus infection. Immunobiology 1990;180:328-38.

[9] Al-Saleh W, Giannini SL, Jacobs N, Moutschen M, Doyen J, Boniver J, Delvenne P. Inverse modulation of intraepithelial Langerhans' cells and stromal macrophage populations in human papillomavirus-associated squamous intraepithelial lesions of the cervix. Virch Arch 1995;427:41-8.

[10] Al-Saleh W, Giannini SL, Jacobs N, Moutschen M, Doyen J, Boniver J, Delvenne P. Correlation of $\mathrm{T}$ helper secretory differentiation and types of antigen-presenting cells in squamous intraepithelial lesions of the uterine cervix. J Pathol 1998;184:283-90.

[11] Rosini S, Caltagirone S, Tallini G, Lattanzio G, Demopoulos R, Piantelli M, Musiani P. Depletion of stromal and intraepithelial antigen-presenting cells in cervical neoplasi in human immunodeficiency virus infection. Hum Pathol 1996;27:834-9.

[12] Gilles C, Piette J, Rombouts S, Laurent C, Foidart JM. Immortallization of human cervical keratinocytes by human papillomavirus 33. Int J Cancer 1993;53:872-9.

[13] Auersperg N, Hawryluk AF. Chromosome observations on three epithelial cell cultures derived from carcinomas of the uterine cervix. J Natl Cancer Inst 1962;28:605-27.

[14] Friedl F, Kimura I, Osato T, Ito Y. Studies on a new human cell line (SiHa) derived from carcinoma of uterus. I. Its establishment and morphology. Proc Soc Exp Biol Med 1970;135:543-5.

[15] Pater M, Pater A. Human papillomavirus types 16 and 18 sequences in carcinoma cell lines of the cervix. Virology 1985;145:313-8

[16] Merrick DT, Blanton RA, Gown AM, McDougall JK. Altered expression of proliferation and differentiation markers in human papillomavirus 16 and 18 immortalized epithelial cells grown in organotypic culture. Am J Pathol 1992;140:167-77.

[17] Hubert P, Greimers R, Franzen-Detrooz E, Doyen J, Boniver J, Delvenne P. In vitro propagated dendritic cells from patients with human papillomavirus-associated preneoplastic lesions of the uterine cervix: use of Flt3 ligand. Cancer Immunol Immunother 1998;47:81-9.

[18] Delvenne P, Al-Saleh W, Gilles C, Thiry A, Boniver J. Inhibition of growth of normal and human papillomavirus-transformed kerationocytes in monolayer and organotypic cultures by interferon- $\gamma$ and tumor necrosis factor- $\alpha$. Am J Pathol 1995;146:58998.

[19] Jacobs N, Moutschen MP, Franzen-Detrooz E, Boniver V, Boniver J, Delvenne P. Organotypic culture of HPV-transformed keratinocytes: a model for testing lymphocyte infiltration of (pre)neoplastic lesions of the uterine cervix. Virch Arch 1998;432:323-30.

[20] Hubert P, van den Brule F, Giannini SL, Franzen-Detrooz E, Boniver J, Delvenne P. Colonization of in vitro-formed cervical human papillomavirus- associated (pre)neoplastic lesions with dendritic cells: role of granulocyte/macrophage colony-stimulating factor. Am J Pathol 1999;154:775-84.

[21] Giannini SL, Al-Saleh W, Piron H, Jacobs N, Doyen J, Boniver J, Delvenne P. Cytokine expression in squamous intraepithelial lesions of the uterine cervix: implications for the generation of local immunosuppression. Clin Exp Immunol 1998;113:183-9.

[22] Tay SK, Jenkins D, Maddox P, Singer A. Lymphocytes phenotypes in cervical intraepithelial neoplasia and human papillomavirus infection. Br J Obstet Gynaecol 1987;94:16-21.

[23] Jacobs N, Renard I, Pisvin S, Hubert P, Boniver J, Delvenne P. IL10 production in cultures of lymphocytes derived from biopsies of normal exocervix, transformation zone and squamous intraepithelial lesion. In: Monsonego, editor. International Proceedings Division, Monduzzi Editore, 2000. pp. 355-362.

[24] Coleman N, Birley HD, Renton AM, Hanna NF, Ryait BK, Byrne M, Taylor-Robinson D, Stanley MA. Immunological events in regressing genital warts. Am J Clin Pathol 1994;102:768-74.

[25] Rosenberg S. The immunotherapy and gene therapy of cancer. J Clin Oncol 1992;10:180-199.

[26] Jacobs N, Greimers R, Mazzoni A, Trebak M, SchaafLafontaine N, Boniver J, Moutschen MP. Further characterization of cytotoxic $\mathrm{T}$ cells generated by short-term culture of human peripheral blood lymphocytes with interleukin-2 and anti-CD3 mAb. Cancer Immunol Immunother 1996;42:369-75.

[27] Friedl P, Noble PB, Zänker KS. T lymphocyte locomotion in a three-dimensional collagen matrix. Expression and function of cell adhesion molecules. J Immunol 1995;154:4973-85.

[28] Ratner S, Patrick P, Bora G. Lymphocyte development of adherence and motility in extracellular matrix during IL-2 stimulation. J Immunol 1992;149:681-8.

[29] Woodworth CD, Simpson S. Comparative lymphokine secretion by cultured normal human cervical keratinocytes, papillomavirus-immortalized, and carcinoma cell lines. Am J Pathol 1993;142:1544-55.

[30] Kaplan G, Walsh G, Guido LS, Meyn P, Burkhardt RA, Abalos RM, Barker J, Frindt PA, Fajardo TT, Celona R, Cohn ZA. Novel responses of human skin to intradermal recombinant granulocyte/macrophage-colony-stimulating factor: Langerhans cell recruitment, keratinocyte growth and enhanced wound healing. J Exp Med 1992;175:1717-28. 